\title{
Effects of core-stabilization and dynamic strengthening exercises on patients with non-specific chronic low back pain in Lagos: A pilot study
}

\author{
Akodu, A.K., Ajepe T.O., Onwuazombe, J.O.
}

\begin{abstract}
Objectives: Exercise is the most widely used form of treatment adopted for gaining relief from low back pain. But the efficacy of core stabilization and dynamic strengthening exercise on cardiopulmonary parameters of non-specific chronic low back pain patients needs to be established. This study therefore compared the effects of core stabilization and dynamic strengthening exercises on pain related disability and selected cardiopulmonary parameters in patients with non-specific chronic low back pain (NSCLBP).
\end{abstract}

Methods: A total of 20 (44.55 \pm 10.78 years) NSCLBP patients participated in this study. They were assigned into two different groups. Group A and B received core stabilization exercise and dynamic strengthening exercise respectively. Participants went through this protocol twice weekly for 4 consecutive weeks and were thereafter assessed for pain-related disability, and selected cardiopulmonary parameters.

Results: The result of this study revealed that both exercises (core stabilization and dynamic) improved pain-related disability $(\mathrm{p}=0.011 ; \mathrm{p}=0.004)$ and some cardiopulmonary parameters in peak expiratory flow rate $(\mathrm{PEFR})(\mathrm{p}=0.001, \mathrm{P}=0.034)$ and rate of perceived exertion $(\mathrm{RPE})(\mathrm{P}=0.001, \mathrm{P}=0.001)$ Pulse rate $(\mathrm{PR})$ $(\mathrm{P}=0.042, \mathrm{P}=0.005)$.

Conclusions: This study showed that both interventions (core stabilization and dynamic strengthening exercise) led to similar result in managing pain-related disability and selected cardiopulmonary parameters except in systolic blood pressure (SBP), Diastolic blood pressure (DBP) and peak expiratory flow rate (PEFR) in patients with NSCLBP when between groups comparison was done.

Keywords: Exercise, cardiopulmonary assessment, chronic low back pain, pilot study

*Corresponding author

Akodu,A.K.

ORCID-NO: http://orcid.org/0000-0003-0262-6376

Email:akoduashiyat@gmail.com,aakodu@unilag.edu.ng

Department of Physiotherapy, College of Medicine, University of Lagos, Nigeria 


\title{
Effets de la stabilisation du noyau et des exercices de renforcement dynamique sur les patients atteints de lombalgie chronique non spécifique à Lagos: Une étude pilote.
}

\author{
Akodu, A.K., Ajepe T.O., Onwuazombe, J.O.
}

\section{Résumé}

Objectifs: L'exercice est la forme de traitement la plus largement utilisée pour soulager les lombalgies. Mais, l'efficacité de la stabilisation du cœur et de l'exercice de renforcement dynamique sur les paramètres cardio-pulmonaires des patients souffrant de lombalgie chronique non spécifique doit être établie. Cette étude a donc comparé les effets des exercices de stabilisation du noyau de renforcement dynamique sur l'incapacité liée à la douleur et certains paramètres cardio-pulmonaires chez les patients souffrant de lombalgie chronique non spécifique. (PCPLC)

Méthodes: Un total de $20(44,55 \pm 10,78$ ans $)$ patients PCPLC ont participé à cette étude. Ils ont été répartis en deux groupes différents. Les groupes A et B ont reçu respectivement un exercice de stabilisation de base et un exercice de renforcement dynamique. Les participants ont suivi ce protocole deux fois par semaine pendant 4 semaines consécutives et ont ensuite été évalués pour leur handicap lié à la douleur et certains paramètres cardio-pulmonaires.

Résultats: Le résultat de cette étude a révélé que les deux exercices (stabilisation du noyau et dynamique) amélioraient l'incapacité liée à la douleur $(p=0,011 ; p=0,004)$ et certains paramètres cardio-pulmonaires du débit expiratoire de pointe (PCPDP) $(\mathrm{p}=0,001, \mathrm{P}=0,034)$ et taux d'effort perçu (RPE) $(\mathrm{P}=0,001, \mathrm{P}=$ $0,001)$ Taux d'impulsion $(\mathrm{TI})(\mathrm{P}=0,042, \mathrm{P}=0,005)$.

Conclusion: Cette étude montre que les deux interventions (stabilisation du noyau et exercice de renforcement dynamique) ont conduit à des résultats similaires dans la gestion de l'incapacité liée à la douleur et de certains paramètres cardio-pulmonaires, sauf dans la pression artérielle systolique (PAS), la pression artérielle diastolique (PAD) et le débit expiratoire de pointe (DEP) chez les patients atteints de PCPLC lorsque la comparaison entre les groupes a été effectuée.

Mots-clés: Exercice, évaluation cardio-pulmonaire, lombalgie chronique, étude pilote

*Corresponding author

Akodu, A.K.

ORCID-NO: http://orcid.org/0000-0003-0262-6376

Email: akoduashiyat@gmail.com, aakodu@unilag.edu.ng

Department of Physiotherapy, College of Medicine, University of Lagos, Nigeria 


\section{INTRODUCTION}

Low back pain (LBP) is a rising primary health care problem affecting over $50 \%$ of the populace world-wide (1). Chronic low back pain constitutes a pronounced societal and financial burden, across different countries (2). Low back pain without a specific pathology such as tumor, fracture and inflammation is known as non-specific low back pain (NSLBP' (2). The life time prevalence of LBP is reported to be as high as $84 \%$ and the prevalence of chronic LBP is about $23 \%$ (2), while NSLBP accounts for greater than $85 \%$ of all LBPs (2). A systematic review and Meta analyses of previous studies on prevalence of low back pain conducted among African population revealed a point, 12 month and lifetime prevalence of $37 \%, 57 \%$ and $47 \%$ respectively (3). While the prevalence of LBP in Nigeria was reported to range from $32.5 \%$ to $73.53 \%$ in a study by Bello and Adebayo (4).

Patients with LBP not only suffer from physical discomfort, but also from functional limitation, which might cause disability that hinder their quality of life (5). The inspiratory muscles and specifically the diaphragm, have a major responsibility of controlling the spine, which is essential when observing postural control (6). However, when the inspiratory muscles are being loaded, the use of proprioceptive signals in the back, essential for controlling stability, is reduced in individuals with low back pain (7). It has also been shown that patients with low back pain are more prone to diaphragm weakness compared to those without it $(7,8)$. Chronic low back pain is associated with increased blood pressure levels at rest which is related to a high sensitivity to acute pain and an elevated level of chronic pain (9). A study by Brody et al (10) showed that there is distorted cardiovascular-pain regulatory system communications in individuals with chronic pain with a lower diastolic blood pressure.

Core-stabilization exercise is a common and active form of exercise prescribed to individuals with non-specific chronic low back pain with the aim of relieving pain, improving quality of life and strengthening the abdominals and supporting the spine (11). The diaphragm, a component of core-stabilization exercise, plays a role in respiratory and trunk stability by controlling intra-abdominal pressure and decreasing the load on the spine by incooperating a synergy between the abdominal and pelvic floor muscles (12). Dynamic strengthening exercise strengthens the spinal column and its supporting structures (13).
Globally, studies have been carried out to determine the effect of core stabilization exercise on pulmonary parameters in different conditions including stroke (14) and substance abuse disorder (15). There is also a previous study on the effect of core stabilization exercise on cardiovascular response of low back pain patients (16). However little is known on the effects of core-stabilization and dynamic strengthening exercises on pain-related disability and selected cardiopulmonary parameters of patients with non-specific chronic low back pain in Nigeria. This study is therefore aimed at comparing the effects of core-stabilization and dynamic strengthening exercises on pain-related disability and selected cardiopulmonary parameters in patients with non-specific chronic low back pain.

\section{MATERIALS AND METHODS}

The study population involved 20 patients with non-specific chronic low back pain in a single blinded randomized controlled study in which participants were blinded to design and hypotheses, group assignment, purpose and type of interventions. The sample size was calculated using the sample size determination for comparing proportions (17). By assuming $\alpha$ value of $1.96, \beta$ value of 0.84 and prevalence of 0.85 (2). They were consecutively recruited from the Physiotherapy Outpatient Clinic of two tertiary hospitals in Lagos state. The participants were consecutive patients referred to physiotherapy outpatient's clinic between April and May 2018. The trial commenced in June and was completed in September, 2018. The approval for this study was obtained from the health research and ethics committee of Lagos University Teaching Hospital, Lagos, Nigeria with reference number: ADM/DCST/HREC/ $\mathrm{APP} / 2185$ and a clinical trial Registration number of: PACTR201809481612827.

Informed written consent was also obtained from the participants before inclusion into the study. Included into the study were participants diagnosed of non-specific chronic low back pain with and without pain radiating to one or both lower limbs (radiculopathy). Excluded from this study were participants who have history of cardiopulmonary diseases prior to onset of non-specific chronic low back pain such as asthma, participants with history of Orthopaedic problems including condition of the back that would have affected their ability to sustain core stabilization exercise and medical or surgical conditions which may hinder exercise performance. 
Clinical data including age and anthropometric parameters measured include height, weight. Body Mass Index (BMI) calculated using the formula weight $/$ height $^{2}$ (18).

\section{Allocation of the participants to groups}

A research assistant co-ordinated the enrollment of participants, generated the random allocation sequence and assigned the participants into the different intervention groups. Participants were blinded to interventions to reduce bias. All referred patients were screened for eligibility.

The eligible participants were randomly assigned into 2 different groups (A and $\mathrm{B}$ ) via simple random sampling technique (lottery method). Twenty-eight (28) participants were recruited into the study, five (5) were excluded based on the exclusion criteria. Thirteen (13) participants were allocated into group A, ten (10) participants into group B but 20 participants completed the study, 3 did not complete due to travel, and illness. The Consort flow diagram showing the recruitment, allocation and progression of participants for the study is reported in figure 1 .

The research assistant was not involved in the treatment of the participants. The researcher $(\mathrm{AK}, \mathrm{JO})$ supervised the intervention protocols.

Participants in groups A and B were scheduled to attend supervised intervention protocols twice weekly for 4 consecutive weeks. Participants in group A were treated with corestabilization exercise for 30 minutes duration (11), while participants in group B were treated with dynamic strengthening exercise (19) for 30 minutes duration.

Assessment of pain related disability: This was done with Pain Disability Index (PDI). This is a simple and quick instrument for measuring the impact that pain has on the ability of the person to participate in necessary life activities. It can be used to evaluate patients initially to monitor them over time and to judge the effectiveness of interventions (20). The participant used an 11point scale ranging from 0 (no disability) to 10 (total disability) to rate the degree to which pain interferes with functioning in seven areas; family/home, recreation, social, occupation, sexual, self-care, life-support. A total score was derived by summing the responses to the 7 items. The higher the index the greater the person's disability due to pain. Previous studies support the use and reliability of the pain disability index
(PDI), the Intraclass correlation coefficients (ICC) for test-retest reliability was 0.91 (20)

Assessment of the cardiovascular parameters: The assessment of the cardiovascular parameters was done by ensuring that the participants were well rested before commencing the assessment. The participants were instructed to rest their arm comfortably on a surface to ensure uniformity of the readings collected.

Pulse Rate: To begin pulse rate measurement, the researcher placed two fingers between the bone and tendon over the left radial artery which is located on the thumb side of the wrist, when the pulse was felt, the researcher counted the number of beats in 30 seconds, multiply this number by 2 to calculate the beats in a minute (21).

Blood Pressure: To begin blood pressure measurement, appropriate blood pressure cuff was made available. The length of the cuffs bladder was equal to eighty percent of the circumference of the forearm. The cuff was wrapped round the forearm with the cuff's lower edge one inch above the antecubital fossa and lightly presses the stethoscope's bell over the brachial artery just below the cuff's edge. The researcher then rapidly inflates the cuff to $180 \mathrm{mmHg}$ and releases air from the cuff at a moderate rate $(3 \mathrm{~mm} / \mathrm{sec})$. The researcher listens with the stethoscope and simultaneously observes the dial or mercury gauge. The first knocking sound (korotkoff) is the participant's systolic pressure. When the knocking sound disappears, that is the diastolic pressure. The researcher recorded the values for each participant (22). The mean arterial pressure (MAP) was computed using the following formula: $M A P=(2[D B P]+S B P) / 3$ while the rate pressure product (RPP) was computed by multiplying the values of the heart rate and systolic blood pressure $(R P P=S B P x H R)$.

Assessment of pulmonary parameters: The respiratory rate was taken as the blood pressure is being measured in sitting position, participants were not aware that their respiratory rates were being taken. The researcher and participant washed their hands. The researcher used the guidelines suggested by American Thoracic Society/European Respiratory Society for the technique (23). The participant were well positioned and the optimal forced manoeuvre was demonstrated to them (24). The spirometer was cleaned with the alcohol swipe and 
disposable mouthpiece was used for each participant. The researcher attached a nose clip on the participants' nose and instructed the participants to inhale completely through the mouth until the lungs are full. Afterwards the participants placed the mouthpiece of the spirometer in the mouth while inhaling air to make the lungs full. The researcher then instructed the participants to exhale forcefully until the air is fully exhaled [24]. This was done for a minimum of three trials and the highest forced vital capacity (FVC); forced expiratory volume in one second $\left(\mathrm{FEV}_{1)}\right.$ and peak expiratory flow rate (PEFR) values were recorded. The participants' rate of perceived exertion was assessed using the Borg scale of perceived exertion. The participants in the 2 groups were reassessed with pain disability index, spirometer, stethoscope and sphygmomanometer at $4^{\text {th }}$ week post intervention

Core stabilization exercise protocol: This comprise of abdominal bracing, Heel slides while bracing the abdomen, Leg Lift with abdominal bracing, Bridging with abdominal bracing , Bridging and leg lift with abdominal bracing, standing with abdominal bracing, Arm lift with bracing in quadruped position, Leg lift with bracing in quadruped position, Alternate arm and leg lift with bracing in quadruped position (11).

Dynamic strengthening exercise protocol: This include traditional curl-up (sit-ups), Knee to chest, Bridging exercises, Prone on elbows, Prone on Hands, Hip extension, Trunk extension (19).

\section{Data Analysis}

The data collected was analyzed using Statistical Package for Social Science (SPSS) version 22 and summarized with the descriptive statistics of frequency, percentage, mean, standard deviation and range. Inferential statistic of paired t-test, independent t-test was used to compare the baseline and post treatment within and between the two groups. Mann-Whitney U as well as Wilcoxon test (for non-parametric variables) was used to compare the quantitative data within and between the two groups. Alpha value was set at $\mathrm{p}<0.05$.

\section{RESULTS}

A total of 23 patients with non-specific chronic low back pain (NSCLBP) participated in this study however 20 participants (11 males and 9 females) completed the study (figure 1).
Thirteen (57\%) participants (7 males and 6 females) were allocated into the corestabilization exercise group and 10(43\%) participants ( 6 males and 4 females) into dynamic strengthening exercise group. The clinical characteristics of participants: The mean ages of participants in groups A and B were 43.00 \pm 8.21 years and $48.67 \pm 13.13$ years respectively, mean weights were $74.12 \pm 10.01 \mathrm{Kg}$ and $75.69 \pm 6.99$ $\mathrm{Kg}$, heights of $1.69 \pm 0.08 \mathrm{~m}$ and $1.69 \pm 0.06 \mathrm{~m}$ and a mean body mass index (BMI) of $25.99 \pm$ $5.62 \mathrm{~kg} / \mathrm{m}^{2}$ and $26.78 \pm 3.99 \mathrm{~kg} / \mathrm{m}^{2}$ respectively were recorded The two groups did not differ significantly in age, height, weight and BMI(Table 1).

Pain-R e lated Dis ability and Cardiopulmonary Parameters within Groups $A \& B$ at Baseline and Post-Intervention

The mean scores of pain-related disability at baseline and at end of $4^{\text {th }}$ week (post intervention) were measured for each group. Wilcoxon test showed that there was significant difference in pain-related disability $(\mathrm{p}=0.011, \mathrm{p}=$ 0.004 ) in each group (A and B) at baseline and post intervention (Table 2).

Paired sample t-test showed that there was significant difference at the end of $4^{\text {th }}$ week (post intervention $)$ in pulse rate $(\mathrm{p}=0.042)$, respiratory rate $(p=0.001)$, forced vital capacity $(p=0.024)$, forced expiratory volume in one second $(p=0.006)$, peak expiratory flow rate $(p=0.001)$ and rate of perceived exertion $(p=0.001)$ in group A, while Paired sample t-test showed that there was significant difference only in pulse rate $(p=$ $0.005)$, peak expiratory flow rate $(p=0.034)$ and rate of perceived exertion $(\mathrm{p}=0.001)$ in group $B$ (Table2).

\section{Comparison of Pain-Related Disability and Cardiopulmonary Parameters at Baseline and Post-Intervention in the two Groups}

The comparison of the mean scores of outcome variables at pre-treatment (baseline) and post-treatment (end of $4^{\text {th }}$ week) between the two groups was presented in table 3. Mann Whitney $U$ test showed that there was no significant difference in the pain-related disability (Median values for groups A and B are 17.0 and 12.0, $\mathrm{p}=0.55$ ) in both groups post intervention.

Paired t-test showed that there was significant difference in pre- and post-treatment intervention assessment for systolic blood pressure $(p=0.01)$, diastolic blood pressure $(p=0.03)$ and peak expiratory flow rate $(p=0.02)$ between both groups. It also showed that there 
was no significant difference in pulse rate $(\mathrm{p}=0.39)$, respiratory rate $(\mathrm{p}=0.15)$, rate pressure product $(\mathrm{p}=0.44)$, mean arterial pressure $(p=0.09)$, forced vital capacity $(p=0.11)$, forced expiratory volume in one second $(p=0.13)$ and rate of perceived exertion $(p=0.07)$ between the two groups (Table 3).

\section{DISCUSSION}

The purpose of this study was to determine the efficacy of core-stabilization exercises and dynamic strengthening exercises on pain-related disability and selected cardiopulmonary parameters in patients with non-specific chronic low back pain (NSCLBP).

The result of this study revealed that the use of therapeutic exercises is effective in the improvement of pain related disability in patients with non-specific chronic low back pain. It was shown that both core-stabilization exercises and dynamic strengthening exercises have similar therapeutic effect in the relief of pain and disability.

The improvement in the outcome measures assessed in the core-stabilization group could be as a result of the reestablishment of the normal control of the deep spinal muscle (DSM), which reduced the activity of more superficial muscles (rectus abdominis, external oblique, internal oblique) which when recruited stabilizes the spine and increase activity in the lumbar muscles. This resulted into decrease in pain and disability level. Furthermore, the co-contraction of the local muscles (DSM) such as transversus abdominis (TrA) and lumbar multifidus (LM) had been reported to be effective in the stabilization of the motion segments of the lumbar spine particularly within the neural zone, thus providing a stable base on which the global muscles (superficial muscles) can safely act (25). The results of this study conforms to the report of the study of Akodu and Akindutire (11) who in their study reported that stabilization exercise was effective in the management of pain-related disability in non-specific chronic low back pain patients. The reduction in pain in the dynamic strengthening exercise group could be due to the recruitment of various muscles of the back. Strengthening the extensor muscles of the back has been found to reduce symptoms in chronic low back pain patients (26).

According to the result of this study, there was significant difference in some of the cardiovascular parameters. This was due to the fact that the exercises (core-stabilization and dynamic strengthening exercise) may have significantly improved the cardiovascular parameters (Systolic blood pressure, diastolic blood pressure, pulse rate, rate pressure product and mean arterial pressure) of NSCLBP patients. The heart rate response to core stabilization exercise involves a combination of cardiovascular, muscular and nervous system. This is achieved by contraction of the skeletal muscles by activation of afferent fibers through stretching and rise in the production of the metabolites from the activity of cells along with increase in plasma catecholamines and reduction in parasympathetic drive causing changes in heart rate (22). In dynamic strengthening exercise there is a rise in the heart rate and utilization of oxygen. A rise in venous return was as a result of increase in stroke volume, leading to a rise in the left ventricular end-diastolic volume referred to as preload. Increased preload stretches the myocardium and causes it to contract more forcefully in agreement with the Frank-Starling law of the heart (22).

The findings of this study showed that in core-stabilization exercises there was clinical improvement in the value of the systolic blood pressure (SBP) which revealed that corestabilization exercises can improve SBP but there was no effect in the diastolic blood pressure (DBP), which could be due to the reduction in pain intensity and return of the normal cardiovascular-pain regulatory system interactions. This proves that core-stabilization has a slight positive effect on the blood pressure in patients with non-specific chronic low back pain. This is in congruence with the study of Vyas et al, (27) who found that there was a significant difference in the blood pressure of the subject studied after lumbar core-stabilization exercise.

Also this study revealed a slight increase in heart rate in core-stabilization exercise group. This in keeping with the study of Subramanian et al, (28) that there was a significant increase in heart rate after core-stabilization exercise; this was adduced to effective isometric contraction that occurs from increased blood flow to the contracting muscles,

In addition to the above it was noted that though dynamic exercises slightly increase the systolic blood pressure, there was a slight reduction in the heart rate in patient non-specific chronic low back pain. This agrees with the study of Kaur and Mann (22) who found an increase in SBP but disagrees with the same study on the increase in heart rate after dynamic exercise. This could be due to the type of population studied which was apparently healthy older adults. There 
was also no significant difference in the DBP, the finding of this study agrees with Kaur and Mann's (22) who found that there was no significant difference in DBP after dynamic exercise training. According to this study however there was no significant difference in the mean arterial pressure (MAP) and rate pressure product (RPP) in both core stabilization and dynamic strengthening exercises.

The outcome of this study showed that both core-stabilization and dynamic strengthening exercises have a significant influence on the SBP and DBP at $4^{\text {th }}$ week intervention in patients with NSCLBP. This simply implies that both exercises can be used to influence the cardiovascular parameters. Caution should be taken when utilizing dynamic exercises in the treatment of NSCLBP, because it causes a slight increase in some cardiovascular parameters (SBP, DBP) while core-stabilization exercise also causes slight increase in heart rate.

The outcome of this study showed that there was a significant improvement in all the pulmonary parameters of NSCLBP patients that were involved in core-stabilization exercise and this improvement was also significant for peak expiratory flow rate (PEFR). This may be because core-stabilization exercise involves strengthening of the core musculature which include the diaphragm, transversus abdominis, lumbar multifidus, internal oblique, external oblique, quadratus lumborum, pelvic floor muscles, rectus abdominis, psoas major and erector spinae. The diaphragm plays a role in respiratory and trunk stability by controlling intra-abdominal pressure and reducing the stress on the spine through cooperative action with the abdominal and pelvic floor muscles (Hodges and Erikson (12), while relaxed expiration is performed by the passive recoil of the diaphragm, it is forced upwards by a rise in intra-abdominal pressure induced by the contraction of the abdominal muscles (13)

This study showed that there was no significant improvement in all the pulmonary parameters except the peak expiratory flow rate (PEFR) and rate of perceived exertion (RPE) in dynamic strengthening exercise group; this could be because dynamic strengthening exercise does not involve the strengthening of the diaphragm and transversus abdominis muscle which are involved in respiratory function. The slight improvement in the PEFR and RPE could be due to a component of core stabilization exercise "bridging with abdominal bracing" which has been found to primarily activate the deep abdominal muscles with minimal activity of the superficial muscles (29). Most likely the strengthening of the deep abdominal muscles led to an improved PEFR and RPE.

\section{CONCLUSION}

The result of this study provides further evidence that patients with non-specific chronic low back pain can achieve significant benefit from core stabilization and dynamic strengthening exercises as regards the cardiopulmonary parameters.

This is the first interventional study in this environment on the effects of core stabilization and dynamic strengthening exercises on pan-related disability and selected cardiopulmonary parameters in patients with non-specific chronic low back pain.

This study is limited due to inadequate time for long term follow up to determine if there would be consistency and improvement in the results and the sample size was small.

Recommendation: Hence there is a need to encourage physiotherapists to prescribe these exercises for the treatment of NSCLBP patients so as to treat the patient holistically due to the affectation of the muscles of respiration in patients with NSCLBP. Physiotherapist should also consider the assessment and management of cardiopulmonary function when treating NSCLBP patients.

Acknowledgment: The authors appreciate and acknowledge the patients that participated in this study.

Conflict of interest: The authors declare that they have no competing interest.

\section{REFERENCES}

1. Freburger JK, Holmes GM, Agans RP, et al. The rising Prevalence of Chronic Low Back Pain. Arch Intern Med. 2009; 169:251-8 https://doi.org/10.1001/archinternmed.2008.543

2. Balague F, Mannion AF, Pellise F, et al. Nonspecific Low Back Pain. Lancet. 2012; 379: 482491. https://doi.org/10.1016/S01406736(11)60610-7

3. Morris LD, Daniel KJ, Ganguli B, Louw QA. An update on the prevalence of low back pain in Africa: a systematic review andmeta-analyses. BMC Musculoskeletal Disorders 2018; 19: 196.

4. Bello B and Bello Adebayo HA. Systematic Review on the Prevalence of Low Back Pain in Nigeria. Middle East J Rehabil Health Stud, 2017; 4(2):e45262.

5. Horng YS, Hwang YH, Wu HC, et al. Predicting 
health-related quality of life in patients with low back pain. Spine. 2005; 30:551-555 https://doi.org/10.1097/01.brs.0000154623.2077 8.f0

6. Hodges PW, Gandevia SC. Change in Intraabdominal Pressure during Postural and Respiratory Activation of the Human Diaphragm. J Appl Physiol. 2000; 89(3): 967-76. https://doi.org/10.1152/jappl.2000.89.3.967 PMid: 10956340

7. Janssens L, Mc Connell AK, Pijnenburg M, et al. Inspiratory Muscle Training Affecting Proprioceptive use and Low Back Pain. Med Sci Sport Exer. $2015 ; 47$ (1): 12 -9. https://doi.org/10.1249/MSS.000000000000038 5 PMid:24870567

8. Janssens L, Brumagne S, McConnell AK, Hermans G, Troosters T, Gayan-Ramirez G. Greater diaphragm fatigability in individuals with recurrent low back pain. Respir Physiol Neurobiol. 2013; 188(2):119-23. doi: 10.1016/j.resp.2013.05.028.

9. Maixner W, Fillingim R. Relationship between pain sensitivity and resting arterial blood pressure in patients with painful temporomandibular disorders. Psychosomatosensory Med. 1997; 59:503-511.https://doi.org/10.1097/00006842199709000-00007

10. Brody S, Angrilla A, Welss U. Somatosensory evoked potentials during baro receptor stimulation in chronic low back pain patients and normal controls. Int J Psychophysiol.1997; 25: 201-210. https://doi.org/10.1016/S01678760(96)00740-4

11. Akodu, AK, Akindutire OM. The effect of stabilization exercise on pain-related disability, sleep disturbance, and psychological status of patients with non-specific chronic low back pain. Korean J Pain. 2018; 31(3):199-205.

12. Hodges PW, Erikson AE . Intra-abdominal pressure increase stiffness of the lumbar spine. $\mathrm{J}$ B i o m e ch. $2005 ; 38(9): 1873-80$. https://doi.org/10.1016/j.jbiomech.2004.08.016 PMid:16023475

13. Jardins TD. Cardiopulmonary Anatomy and Physiology: Essentials for respiratory care (4th Edition). 2002; Pg 49-55.

14. Oh DS, Park SE. The effect of lumbar stabilization exercise on the pulmonary function of stroke patients J. Phys. Ther. Sci. 2016, 28: 1896-1900

15. Mustafaoglu R, Demir R, Demirci AC, Yigit Z. Effects of core stabilization exercises on pulmonary function, respiratory muscle strength, and functional capacity in adolescents with substance use disorder: Randomized controlled trial. 2019 ; Pediatr Pulmonol. https://doi.org/10.1002/ppul.24330

16. Datta A, Sen S and Shivpriya. Efficacy of Core Strengthening on Cardiovascular Fitness, Flexibility and Strength on Patient with Low Back Pain. Journal of Novel Physiotherapies 2014;. 4:202.

17. Wang H. and Chow SC. Sample Size Calculation for Comparing Proportions 2007. Wiley Encyclopedia of Clinical Trials.

18. Stewart AD, Marfell-Jones M, Olds T, Hans De Ridder J. International Standards for Anthropometric Assessment. International Society for the Advancement of Kinanthropometry (ISAK) 2011

19. Aly SM. Trunk Muscle Response to Core Stability Exercises in Patients with Chronic Low Back Pain: A randomized controlled trial. IJPR. 2017; 5(1): 1836-45.

20. Grönblad M, Hupli M, Wennerstrand P, Järvinen E, Lukinmaa A, Kouri JP et al. Intelcorrelation and Test-Retest Reliability of the Pain Disability Index (PDI) and the Oswestry Disability Questionnaire (ODQ) and Their Correlation with Pain Intensity in Low Back Pain Patients. Clin J Pain . 1993; 9(3):189-195

21. Pickering D. How to measure the pulse. Community Eye Health. 2013; 26(82):37.

22. Kaur J and Mann R. Cardiovascular Response to Exercise Static versus Dynamic. AIMDR. 2016; 2(6):4https://doi.org/10.21276/aimdr.2016.2.6.P $\mathrm{H} 1$

23. Adegoke BOA, Akinremi AA, Akintobi AE. Effects of tobacco smoking on pulmonary function indices among undergraduate students. Afr J Biomed Res. 2015; 9-11.

24. Coates AL, Graham BL, Mc Fadden RC, et al. Spirometry in primary care. Can Respir J. 2013; 20(1): 13-22.

25. Akodu AK, Akinbo SRA, Odebiyi DO. Effect of stabilization exercise on Lumbar Multifudus muscle thickness in patients with non-specific chronic low back pain. IRJ. 2014; 12(20): 6-10.

26. Bhadauria EA, Gurudut P. Comparative Efficacy of Lumbar Stabilization, Dynamic Strengthening and Pilates on Chronic Low Back Pain: Randomized control trial. J Exerc Rehabil. 2017; 13(4):477-485.

27. Vyas HP, Shah S, Vyas NJ. Cardiovascular Responses to Lumbar Core Muscle Stabilization exercise in Young Adults having Postural Low Back Pain. Natl J Physiol Pharm Pharmacol. 2015;20.5(2):98-100. 
Table 1: Demographic Characteristics of the Participants

\begin{tabular}{|c|c|c|c|c|c|}
\hline & $\begin{array}{l}\text { All participants } \\
X \pm \text { SD; } N=\mathbf{2 0}\end{array}$ & $\begin{array}{l}\text { GRP A } \\
X \pm S D ; n=11\end{array}$ & $\begin{array}{l}\text { GRP B } \\
X \pm S D ; n=9\end{array}$ & t-test & P-value \\
\hline Age (years) & $\begin{array}{l}45.55 \pm 10.79 \\
74.83 \pm 8.60\end{array}$ & $\begin{array}{l}43.00 \pm 8.21 \\
74.12 \pm 10.01\end{array}$ & $\begin{array}{l}48.67 \pm 13.13 \\
75.69 \pm 6.99\end{array}$ & $\begin{array}{l}1.18 \\
0.40\end{array}$ & $\begin{array}{l}0.25 \\
0.70\end{array}$ \\
\hline $\begin{array}{l}\text { Weight }(\mathrm{kg}) \\
\text { Height }(\mathrm{m}) \\
\text { BMI }\left(\mathrm{Kg} / \mathrm{m}^{2}\right)\end{array}$ & $\begin{array}{l}1.69 \pm 0.07 \\
26.34 \pm 4.26\end{array}$ & $\begin{array}{l}1.69 \pm 0.08 \\
25.99 \pm 5.62\end{array}$ & $\begin{array}{l}1.69 \pm 0.06 \\
26.78 \pm 3.99\end{array}$ & $\begin{array}{l}0.25 \\
0.40\end{array}$ & $\begin{array}{l}0.81 \\
0.69\end{array}$ \\
\hline
\end{tabular}

Significant at $\mathrm{p} \leq 0.05$

KEY:

$\mathrm{X} \pm \mathrm{SD} \quad=$ Mean \pm Standard Deviation

BMI $=$ Body Mass Index

GRP A- Group A = Core-stabilization exercise

GRP B- Group B = Dynamic strengthening exercise

t-test $=$ Independent test

Table 2: Comparison of pain related disability and Cardiopulmonary Parameters within the groups at pre treatment (Baseline) and post- treatment (End of $4^{\text {th }}$ Week)

\begin{tabular}{|c|c|c|c|c|c|c|}
\hline Groups & PARAMETER & $\begin{array}{l}\text { PRE- Rx } \\
\text { (Baseline) } \\
\text { Mean } \pm \text { SD }\end{array}$ & $\begin{array}{l}\text { POST }- \text { Rx } \\
{\text { (End of } 4^{\text {th }}}^{\text {Week) }} \\
\text { Mean } \pm \text { SD } \\
\end{array}$ & t- test & $\mathbf{z}$ & P-value \\
\hline $\begin{array}{l}\text { GRPA } \\
\mathrm{n}=11\end{array}$ & PD & $27.82 \pm 11.44$ & $18.55 \pm 12.20$ & - & 0.00 & $0.011 *$ \\
\hline & $\begin{array}{l}\text { DBP(mmHg) } \\
\text { SBP(mmHg) } \\
\text { PR(b/m) } \\
\text { RR(c/m) } \\
\text { RPP(mmHg/m) } \\
\text { MAP(mmHg) } \\
\text { FVC(L) } \\
\text { FEV1(L) } \\
\text { PEFR(L/s) } \\
\text { RPE }\end{array}$ & $\begin{array}{l}73.45 \pm 4.11 \\
118.73 \pm 5.68 \\
68.18 \pm 7.01 \\
18.36 \pm 2.50 \\
8105.45 \pm 1015.02 \\
88.55 \pm 3.85 \\
2.22 \pm 0.57 \\
2.10 \pm 0.56 \\
5.95 \pm 1.95 \\
6.82 \pm 0.87\end{array}$ & $\begin{array}{l}73.27 \pm 5.75 \\
114.55 \pm 3.36 \\
69.82 \pm 6.60 \\
20.18 \pm 2.44 \\
8005.09 \pm 884.98 \\
78.73 \pm 26.47 \\
2.45 \pm 0.53 \\
2.37 \pm 0.50 \\
7.03 \pm 1.71 \\
4.45 \pm 1.44\end{array}$ & $\begin{array}{l}0.11 \\
2.12 \\
2.32 \\
5.59 \\
0.54 \\
1.29 \\
2.65 \\
3.52 \\
4.75 \\
6.50\end{array}$ & & $\begin{array}{l}0.918 \\
0.060 \\
0.042^{*} \\
0.001^{*} \\
0.603 \\
0.227 \\
0.024^{*} \\
0.006^{*} \\
0.001^{*} \\
0.001^{*}\end{array}$ \\
\hline \multicolumn{7}{|l|}{$\begin{array}{l}\text { GRP B } \\
n=9\end{array}$} \\
\hline & $\begin{array}{l}\text { PD } \\
\text { DBP(mmHg) } \\
\text { SBP(mmHg) } \\
\text { PR(b/m) } \\
\text { RR(c/m) } \\
\text { RPP(mmHg/m) } \\
\text { MAP(mmHg) } \\
\text { FVC(L) } \\
\text { FEV1(L) } \\
\text { PEFR(L/s) } \\
\text { RPE }\end{array}$ & $\begin{array}{l}23.89 \pm 11.11 \\
77.78 \pm 6.89 \\
124.44 \pm 6.23 \\
69.56 \pm 9.68 \\
19.78 \pm 2.33 \\
8630.22 \pm 1054.23 \\
93.33 \pm 5.82 \\
1.86 \pm 0.63 \\
1.83 \pm 0.63 \\
4.56 \pm 1.84 \\
6.22 \pm 1.20\end{array}$ & $\begin{array}{l}15.33 \pm 10.10 \\
80.00 \pm 6.63 \\
125.78 \pm 11.33 \\
66.67 \pm 9.33 \\
18.67 \pm 2.00 \\
8347.11 \pm 1045.27 \\
95.26 \pm 7.34 \\
2.02 \pm 0.58 \\
1.97 \pm 0.61 \\
5.14 \pm 1.71 \\
3.44 \pm 0.73\end{array}$ & $\begin{array}{l}- \\
1.75 \\
0.47 \\
3.83 \\
1.89 \\
1.80 \\
1.16 \\
1.21 \\
1.16 \\
2.55 \\
5.98\end{array}$ & 1.00 & $\begin{array}{l}0.004^{*} \\
0.117 \\
0.652 \\
0.005^{*} \\
0.095 \\
0.109 \\
0.281 \\
0.261 \\
0.282 \\
0.034^{*} \\
0.001^{*}\end{array}$ \\
\hline
\end{tabular}

*Significant difference $\mathrm{p} \leq 0.05$

Key:

PD: Pain Related Disability, SBP: Systolic Blood Pressure, DBP: Diastolic Blood Pressure, PR: Pulse Rate, RR: Respiratory Rate, RPP: Rate Pressure Product, MAP: Mean Arterial Pressure, FVC: Forced Vital Capacity, FEV1: Forced expired volume in 1 second, PEFR: Peak Expiratory Flow Rate, RPE: Rate of perceived Exertion, GRP A- Group A: Core-stabilization exercise, GRP B- Group B: Dynamic strengthening exercise, t-test - Paired sample t-test Z-test- Wilcoxon test 
Table 3: Comparison of Cardiopulmonary Parameters at Baseline and e nd of $4^{\text {th }}$ Week between the two groups.

\begin{tabular}{|c|c|c|c|c|c|c|}
\hline Groups & PARAMETER & $\begin{array}{c}\text { GRPA } \\
\mathbf{n}=\mathbf{1 1} \\
\text { Mean } \pm \text { SD }\end{array}$ & $\begin{array}{c}\text { GRP B } \\
\mathbf{n}=\mathbf{9} \\
\text { Mean } \pm \text { SD }\end{array}$ & u- test & t-test & P-value \\
\hline \multirow[t]{11}{*}{ Baseline } & $\mathrm{PD}$ & $27.92 \pm 11.44$ & $23.89 \pm 11.11$ & 61.00 & - & 0.41 \\
\hline & $\mathrm{DBP}(\mathrm{mmHg})$ & $73.45 \pm 4.11$ & $77.78 \pm 6.89$ & & 1.74 & 0.10 \\
\hline & $\mathrm{SBP}(\mathrm{mmHg})$ & $118.73 \pm 5.68$ & $124.00 \pm 6.23$ & & 2.15 & $0.05 *$ \\
\hline & $\mathrm{PR}(\mathrm{b} / \mathrm{m})$ & $68.18 \pm 7.01$ & $69.56 \pm 9.68$ & & 0.37 & 0.72 \\
\hline & $\mathrm{RR}(\mathrm{c} / \mathrm{m})$ & $18.66 \pm 2.50$ & $19.78 \pm 2.33$ & & 1.30 & 0.21 \\
\hline & $\mathrm{RPP}(\mathrm{mmHg} / \mathrm{m}$ & $8630.22 \pm 1054.23$ & $\begin{array}{l}8105.45 \pm 1105.0 \\
2\end{array}$ & & 1.13 & 0.27 \\
\hline & MAP(mmHg) & $88.55 \pm 3.85$ & $93.33 \pm 5.82$ & & 2.21 & $0.04 *$ \\
\hline & $\mathrm{FVC}(\mathrm{L})$ & $2.21 \pm 0.57$ & $1.86 \pm 0.63$ & & -1.31 & 0.21 \\
\hline & FEV1(L) & $2.10 \pm 0.56$ & $1.83 \pm 0.66$ & & -0.97 & 0.35 \\
\hline & PEFR(L/s) & $5.95 \pm 1.95$ & $4.56 \pm 1.83$ & & -1.62 & 0.12 \\
\hline & RPE & $6.82 \pm 0.87$ & $6.22 \pm 1.04$ & & -1.28 & 0.22 \\
\hline \multirow{11}{*}{$\begin{array}{l}\text { End of } 4^{\text {th }} \\
\text { Week }\end{array}$} & PD & $18.55 \pm 12.20$ & $15.33 \pm 10.10$ & 57.50 & & 0.55 \\
\hline & DBP(mmHg) & $73.27 \pm 5.27$ & $80.00 \pm 6.63$ & & 2.43 & $0.03 *$ \\
\hline & $\mathrm{SBP}(\mathrm{mmHg})$ & $114.55 \pm 3.36$ & $125.78 \pm 11.33$ & & 3.14 & $0.01 *$ \\
\hline & $\mathrm{PR}(\mathrm{b} / \mathrm{m})$ & $69.82 \pm 6.66$ & $66.67 \pm 9.33$ & & -0.88 & 0.39 \\
\hline & $\mathrm{RR}(\mathrm{c} / \mathrm{m})$ & $20.18 \pm 2.44$ & $18.67 \pm 2.00$ & & -1.49 & 0.15 \\
\hline & $\mathrm{RPP}(\mathrm{mmHg} / \mathrm{m}$ & $8347.11 \pm 1045.27$ & $8005.09 \pm 884.98$ & & 0.79 & 0.44 \\
\hline & $\mathrm{MAP}(\mathrm{mmHg})$ & $78.73 \pm 26.47$ & $95.26 \pm 7.34$ & & 1.81 & 0.09 \\
\hline & FVC(L) & $2.45 \pm 0.53$ & $2.02 \pm 0.58$ & & -1.71 & 0.11 \\
\hline & FEV1(L) & $2.37 \pm 0.50$ & $1.97 \pm 0.61$ & & -1.58 & 0.13 \\
\hline & PEFR(L/s) & $7.03 \pm 1.71$ & $5.14 \pm 1.71$ & & -2.46 & $0.02 *$ \\
\hline & RPE & $4.45 \pm 1.44$ & $3.44 \pm 0.73$ & & -1.91 & 0.07 \\
\hline
\end{tabular}

*Significant difference $\mathrm{p} \leq 0.05$

Key:

PD: Pain Related Disability SBP: Systolic Blood Pressure, DBP: Diastolic Blood Pressure, PR: Pulse Rate, RR: Respiratory Rate, RPP: Rate Pressure Product, MAP: Mean Arterial Pressure, FVC: Forced Vital Capacity, FEV1: Forced expired volume in 1 second, PEFR: Peak Expiratory Flow Rate, RPE: Rate of perceived Exertion, GRP A - Group A: Core-stabilization exercise, GRP B- Group B: Dynamic strengthening exercise, t-test - Paired sample t-test, u-test- Mann Whitney U 


\section{CONSORT 2010 Flow Diagram}

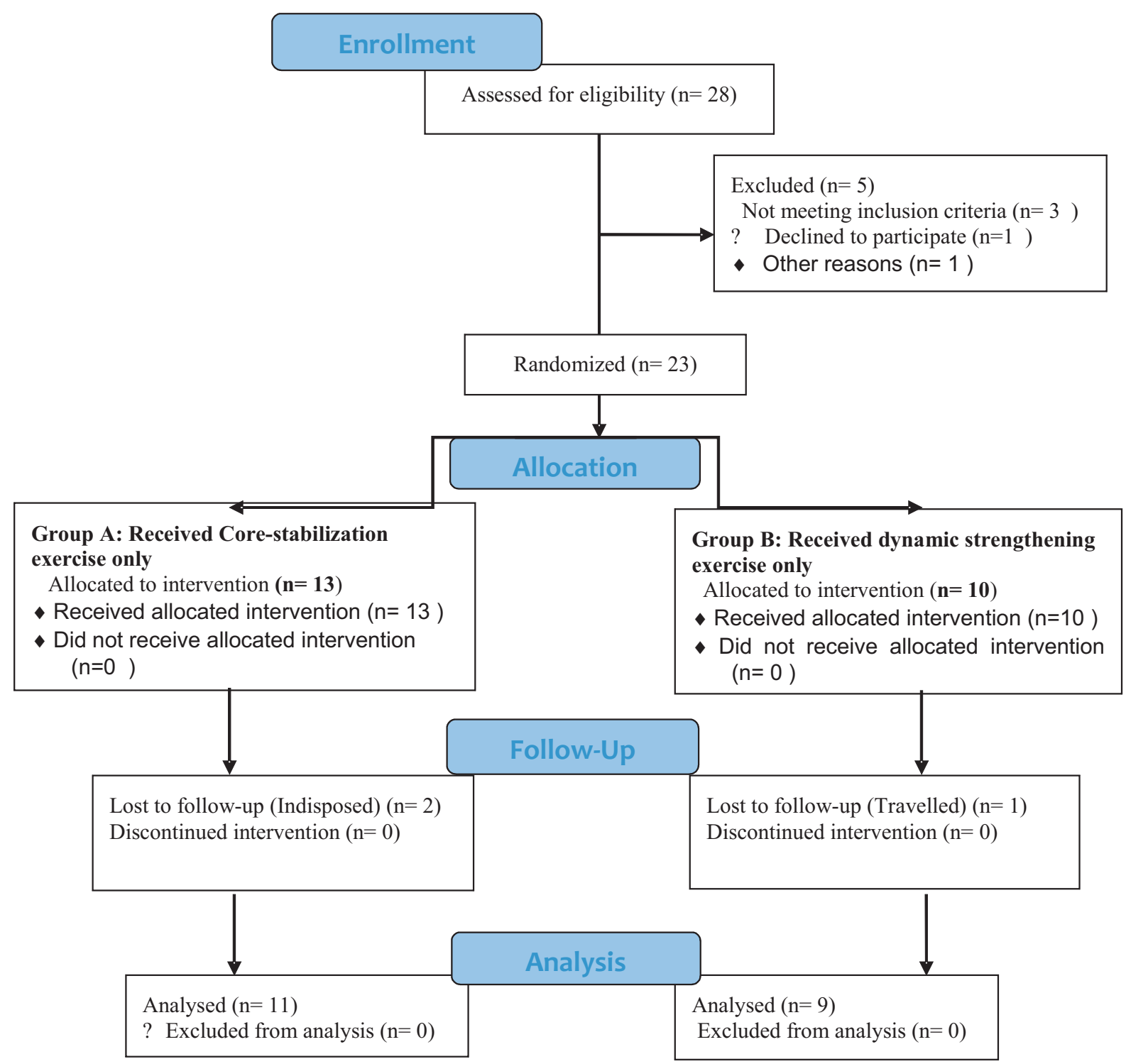

